\title{
Factors associated with low birthweight among newborns delivered at public health facilities of Nekemte town, West Ethiopia: a case control study
}

Shimelis Girma', Teshale Fikadu² ${ }^{2 *}$, Eskeziyaw Agdew², Desta Haftu², Genet Gedamu², Zeritu Dewana ${ }^{3}$ and Bereket Getachew ${ }^{4}$

\begin{abstract}
Background: Low birthweight (LBW) remains the most important risk factor which attributed to mortality of 15-20\% of newborns across the globe. An infant with low birthweight is more likely to have stunting in childhood and develop markers of metabolic risk factors at his later age. Furthermore, LBW is a risk for inter-generational assaults of malnutrition as it is the risk for sub optimal growth until adulthood, affecting women's and male's reproductive capabilities. Thus, there is enough concern to study the determinants of LBW across different settings. Accordingly, this study was conducted to assess the determinants of low birthweight s in public health facilities of Nekemte town, West Ethiopia.

Methods: Facility based unmatched case control study was employed from February to April 2017. The data were collected using structured, pretested interviewer administered questionnaire in all public health facilities of Nekemte town. Consecutive live births of less than $2500 \mathrm{~g}$ in each of the hospitals and health centres were selected as cases and succeeding babies with weights of at least $2500 \mathrm{~g}$ as controls. Data were entered in to Epi-data software version 3.1 and exported to SPSS Version 21 and analyzed using frequency, cross-tabs and percentage. Factors with $p$-value $<0.25$ in Bivariate analysis were entered in to multivariable logistic regression and statistical significance was considered at $p$-value $<0.05$.

Result: A total 279 (93 cases \&186 controls) were included in the study with a mean birthweight of 2138.3 $\mathrm{g} \pm$ SD 206.87 for cases and $3145.95 \mathrm{~g} \pm$ SD 415.98 for controls. No iron-folate supplementation ( $A O R=2.84$, $95 \% \mathrm{Cl}, 1.15-7.03)$, no nutritional counselling $(A O R=4.05,95 \% \mathrm{Cl}, 1.95-8.38)$, not taking snacks ( $A O R=3.25$, $95 \% \mathrm{Cl}, 1.64-6.44)$, maternal under nutrition $(\mathrm{AOR}=5.62,95 \% \mathrm{Cl}, 2.64-11.97)$, anemia $(\mathrm{AOR}=3.54,95 \% \mathrm{Cl}, 1.46-$ $8.61)$ and inadequate minimum dietary diversity score of women MDDS-W (AOR $=6.65,95 \% \mathrm{Cl}, 2.31-19.16)$ were factors associated with low birthweight.

Conclusion: Lacking nutrition counselling during pregnancy, lacking iron/folic acid supplementation during pregnancy, not taking snacks during pregnancy, maternal under-nutrition, maternal anemia and inadequate minimum dietary diversity score of women (MDDS-W) were independently associated with LBW. Thus, public health intervention in the field of maternal and child health should address these determinants.
\end{abstract}

Keywords: Low birthweight, Maternal nutritional status, Nekemte town

\footnotetext{
* Correspondence: fikaduteshale1@gmail.com

${ }^{2}$ Department of Public Health, College of Medicine and Health Science, Arba

Minch University, Arba Minch, Ethiopia

Full list of author information is available at the end of the article
}

(c) The Author(s). 2019 Open Access This article is distributed under the terms of the Creative Commons Attribution 4.0 International License (http://creativecommons.org/licenses/by/4.0/), which permits unrestricted use, distribution, and reproduction in any medium, provided you give appropriate credit to the original author(s) and the source, provide a link to the Creative Commons license, and indicate if changes were made. The Creative Commons Public Domain Dedication waiver (http://creativecommons.org/publicdomain/zero/1.0/) applies to the data made available in this article, unless otherwise stated. 


\section{Background}

The World Health Organization (WHO) defined low birthweight (LBW) as weight less than $2500 \mathrm{~g}$ at birth. Low birthweight contributes to a variety of pitiable health outcomes [1].

The majority of LBW in low income countries is due to IUGR, while it is mostly due to preterm birth in high income countries. Although in many cases, the causes of prematurity are vague, they may include maternal high blood pressure, acute infections, hard physical work, multiple births, stress, anxiety, and other psychological factors such as gender-based violence. The causes of IUGR include, poor nutritional status of the mother at conception, low weight gain during pregnancy due to insufficient dietary intake or extra expenditure of calories (hard work), short maternal height due to youthful under-nutrition and infections, anemia, acute and chronic infections that could result in under-nutrition and consecutive poor pregnancy outcomes including LBW [2].

LBW is a global public health challenging problem. Its high priority stems from the fact that it is the major determinant of infant morbidity and that it contributes markedly to the overall burden of childhood death. LBW has also been linked to the high prevalence of stunting seen in low income countries and may be important in the ethology of chronic dietary diseases such as obesity, diabetes and cardiovascular diseases in adulthood [2].

Worldwide more than 20 million low birthweight occur annually with the incidence of 15 to $20 \%$, majority of this occur in low- and middle-income countries and 95.6\% occur in developing nations. Its regional estimate was $28 \%$ in South Asia, $13 \%$ in sub-Saharan Africa and $13 \%$ in least developed country [1, 3] As EDHS 2011 report in Addis Ababa, Ethiopia 11.4\% are LBW [4].

Being born with LBW is generally recognized as a disadvantage for the infant. Among all neonatal death 60 to $80 \%$ occur due to LBW. It is an important cause of perinatal mortality and both short- and long-term infant and childhood morbidity. Mortality rate of LBW infant were up to 40 times higher than infants with birthweights of at least $2500 \mathrm{~g}$, and they are many times more likely to end up with long-term handicapping conditions [5-11].

A recent study done in India has reported that maternal age ( $<19$ years), rural residence, maternal weight $(<45 \mathrm{~kg})$, gestational age ( $<37$ weeks), bad obstetric history and Pregnancy-induced hypertension have a strong association with low birthweight. A number of studies have shown correlates of infant's maternal nutritional status, young maternal age, bad obstetric history, maternal anemia and rural settlements, antenatal care received, prematurity, the birth interval with low birthweight [12-29]. However, the majority of these studies did not address maternal nutritional status and maternal dietary practices. Therefore, the aim of this study was to determine nutritional and others factors associated with LBW among newborns delivered at public health facilities of Nekemte town, West Ethiopia.

\section{Methods and materials \\ Study setting and sampling}

An institution-based unmatched case control study was employed in public health facilities of Nekemte town from March to April, 2017. The town is located $340 \mathrm{~km}$ west of Addis Ababa (the capital city of Ethiopia). It had an estimated total population of 110,688 people in the year 2016/17 which is projected from the 2007 Ethiopia Central Statistical Agency. There are two public health centres and two hospitals providing delivery service for pregnant women and these public health facilities were included in the study.

Cases were all live births of less than $2500 \mathrm{~g}$ while controls were all live birthweight of at least $2500 \mathrm{~g}$.

Sample size was calculated using Epi info version 7 by assuming the proportion of women with anemia among controls and cases were 11.6 and $25.8 \%$ respectively, 95\% CI, $80 \%$ power, case to control ratio of $1: 2$ and accounted for $10 \%$ possible non-response. The total sample size was 279 (93 cases and 186 controls). To calculate sample size, maternal anemia was chosen as an independent variable since it gave maximum sample size. The two hospitals and two health centres found in Nekemte town were included. The sample is allocated proportionally based on the number of births in a 5 months period. Consecutive sampling was used to select cases and systematic random sampling was used to select controls. Controls were selected from the same health facility from which cases were selected.

\section{Data collection and measurements}

Semi structured interviewer administered questionnaires that contain; nutritional and dietary related factors, socio demographic and socio-economic related factors, medical and obstetrics related factors, behaviour related factors, environmental related factors and infant related factors. The interviews were conducted at the health facility after the mother had given birth. Questionnaires were prepared in English and translated to local language (Afaan Oromo) by language experts and retranslated back to English by another person to check consistency. Food security status of households was determined based on nine standard household food insecurity (HFIAS) questions that were validated for a low income country. Maternal dietary diversity (MDD-W) was determined by using 24-h dietary recall method by MDD-W. Maternal haemoglobin level was reviewed from client card from each public health facilities to determine anaemia.

The neonate's weight was measured using a balanced Seca scale (Germany) to the nearest $0.01 \mathrm{~g}$ 
Table 1 Socio-economic and demographic characteristics of mothers of the study participants in Nekemte town, West Ethiopia, 2017

\begin{tabular}{|c|c|c|c|}
\hline Variables & Case No (\%) & Controls № (\%) & $p$-value \\
\hline \multicolumn{4}{|l|}{ Infant sex } \\
\hline Male & $49(52.7)$ & $117(62.9)$ & \\
\hline Female & $44(47.3)$ & $69(37.1)$ & 0.052 \\
\hline \multicolumn{4}{|l|}{ Maternal age (year) } \\
\hline$\leq 20$ & $9(9.7)$ & $32(17.2)$ & 0.001 \\
\hline $21-35$ & $77(82.8)$ & $147(79.6)$ & \\
\hline$>35$ & $7(7.5)$ & $6(3.2)$ & \\
\hline \multicolumn{4}{|l|}{ Residence } \\
\hline Rural & $41(44.1)$ & $75(40.3)$ & 0.28 \\
\hline Urban & $52(55.9)$ & $111(59.7)$ & \\
\hline \multicolumn{4}{|l|}{ Religion } \\
\hline Muslim & $69(74.2)$ & $140(75.3)$ & 0.68 \\
\hline Orthodox & $20(21.5)$ & $42(22.6)$ & \\
\hline Others & $4(4.3)$ & $4(2.2)$ & \\
\hline \multicolumn{4}{|l|}{ Ethnicity } \\
\hline Amhara & $77(82.8)$ & $168(90.3)$ & 0.27 \\
\hline Oromo & $10(10.8)$ & $7(3.8)$ & \\
\hline Others & $6(6.5)$ & $11(5.9)$ & \\
\hline \multicolumn{4}{|l|}{ Marital status } \\
\hline Married & 87 (93.5) & $172(92.5)$ & 0.38 \\
\hline Single/ divorced & $6(6.5)$ & $14(7.5)$ & \\
\hline \multicolumn{4}{|c|}{ Educational status of mothers } \\
\hline Informal education & $32(34.4)$ & $32(17.2)$ & 0.001 \\
\hline Formal education & $61(65.6)$ & $154(82.8)$ & \\
\hline \multicolumn{4}{|l|}{ Occupation of mothers } \\
\hline Employed & $17(18.3)$ & 63 (33.9) & 0.001 \\
\hline Merchant & $5(5.4)$ & $24(12.9)$ & \\
\hline Housewife & 65 (69.9) & $91(48.9)$ & \\
\hline Others & $6(6.5)$ & $8(4.3)$ & \\
\hline \multicolumn{4}{|l|}{ Wealth index } \\
\hline Lower & $58(62.4)$ & $101(54.3)$ & 0.53 \\
\hline Middle & $16(17.2)$ & 49 (26.3) & \\
\hline Upper & 19 (20.4) & 36 (19.4) & \\
\hline
\end{tabular}

within 1 hours of birth. The mid-upper arm circumference (MUAC) of the mother was measured right after delivery using flexible non-stretchable standard tape measure.

\section{Data analysis}

Data was checked for completeness, coded and entered into Epi data version 3.1 and exported to SPSS version 21.0 statistical software for analysis. Descriptive statistics were presented using standard statistical parameters
Table 2 Nutritional related characteristics of mothers of study participants in Nekemte town, West Ethiopia, 2017

\begin{tabular}{|c|c|c|c|}
\hline Variables & Case No (\%) & Controls No $(\%)$ & $p$-value \\
\hline \multicolumn{4}{|l|}{$\overline{M U A C}$} \\
\hline$<23$ & $49(52.7)$ & $25(13.4)$ & \multirow[t]{2}{*}{0.001} \\
\hline$\geq 23$ & $44(47.3)$ & $161(86.6)$ & \\
\hline \multicolumn{4}{|c|}{ Iron and folate supplementation } \\
\hline Yes & $64(68.8)$ & $166(89.2)$ & \multirow[t]{2}{*}{0.001} \\
\hline No & $29(31.2)$ & $20(10.8)$ & \\
\hline \multicolumn{4}{|c|}{ Any multivitamin } \\
\hline Yes & $9(9.7)$ & $36(19.4)$ & \multirow[t]{2}{*}{0.018} \\
\hline No & $84(90.3)$ & $150(80.6)$ & \\
\hline \multicolumn{4}{|c|}{ Nutritional counseling during pregnancy } \\
\hline Yes & $40(43.0)$ & $153(82.3)$ & \multirow[t]{2}{*}{0.001} \\
\hline No & $53(57.0)$ & $33(17.7)$ & \\
\hline \multicolumn{4}{|c|}{ Taking snacks during pregnancy } \\
\hline Yes & $34(36.6)$ & $134(72)$ & \multirow[t]{2}{*}{0.001} \\
\hline No & $59(63.4)$ & $52[27]$ & \\
\hline \multicolumn{4}{|c|}{ Minimum dietary diversity score of women } \\
\hline Inadequate & $87(93.5)$ & $117(62.9)$ & \multirow[t]{2}{*}{0.001} \\
\hline Adequate & $6(6.5)$ & $69(37.1)$ & \\
\hline \multicolumn{4}{|l|}{ Anemia } \\
\hline Yes & $30(32.3)$ & $17(9.1)$ & \multirow[t]{2}{*}{0.001} \\
\hline No & $63(67.7)$ & $169(90.9)$ & \\
\hline \multicolumn{4}{|c|}{ Eating out of home } \\
\hline Yes & $81(87.1)$ & $167(89.8)$ & \multirow[t]{2}{*}{0.251} \\
\hline No & $12(12.9)$ & 19 (10.2) & \\
\hline \multicolumn{4}{|l|}{ Chat chewing } \\
\hline Yes & $33(35.5)$ & $50(26.9)$ & \multirow[t]{2}{*}{0.071} \\
\hline No & $60(64.5)$ & $136(73.1)$ & \\
\hline \multicolumn{4}{|c|}{ Alcohol consumption } \\
\hline Yes & $5(5.4)$ & $15(8.1)$ & \multirow[t]{2}{*}{0.215} \\
\hline No & 88 (94.6) & $171(91.9)$ & \\
\hline
\end{tabular}

such as percentages, means and standard deviations. Bivariate analysis was done and all explanatory variables with a $p$-value less than 0.25 were included in multivariable analysis. Multi variable conditional logistic regression analysis was employed to determine independent determinant factors.

Wealth index was calculated as a composite indicator of living standard by considering variables related to ownership of household assets. The computation was prepared using principal component analysis and a continuous variable was generated by summing up the principal components into one. Household food insecurity access scale scores $(0-27)$, were summed to produce an index of household food insecurity. As to maternal dietary diversity scores, a pregnant woman was assigned to 
be adequate if her MDD-W score was $>5$ or inadequate with a MDD-W score $<5$. Hosmer and lemeshow test was used to asses model fitness $(p=0.75)$ and variance inflation factor (VIF) and tolerance test were used to check multicollinearity.

\section{Results}

Total of 279 (93 cases and 186 controls) were participants in the study. Mean birthweight of cases and controls were $2138.28 \mathrm{~g} \pm 206.87$ and $3145.16 \mathrm{~g} \pm 414.99$. Majority of the newborns were males 49 (52.7\%) for cases and $117(62.9 \%)$ for controls. Fifty-two $(55.9 \%)$ of cases and 111(59.7) of controls came from an urban setting. Mothers of 61cases (65.6\%) and 154 controls (82.5\%) did not attend formal education. (Table 1).

Mean maternal height for cases and controls was 155 $\mathrm{cm} \pm 0.07$ and $159 \mathrm{~cm} \pm 0.07$. Under-nutrition in mothers as defined by MUAC $<23 \mathrm{~cm}$ was $52.7 \%$ for cases and $13.4 \%$ for controls (Table 2).

Findings of multivariable logistic regression indicated that lack of maternal iron and folic acid supplementation during pregnancy $(\mathrm{AOR}=2.84,95 \% \mathrm{CI}, 1.15-7.03)$, lack of nutritional counselling during the current pregnancy ( $\mathrm{AOR}=4.05,95 \% \mathrm{CI}, 1.95-8.38)$, not taking snacks $(\mathrm{AOR}=3.25,95 \% \mathrm{CI}, 1.64-6.44)$, maternal under nutrition $(\mathrm{AOR}=5.62,95 \% \mathrm{CI}, 2.64-11.97)$, and maternal anaemia (AOR $=3.54,95 \% \mathrm{CI}, 1.46-8.61$ ) were positively associated with low birthweight (Table 3).

\section{Discussion}

LBW is a global challenging public health problem. Its high priority stems from the fact that it is the major predictor of infant morbidity and mortality [30].

In this study mothers not counselled about nutrition during pregnancy had significantly higher odds of LBW than their counterparts. Nutritional counselling may improve their feeding behaviour and hence, their nutritional status which may help mothers to decrease the risk of delivering LBW babies. The finding was consistent with studies done in Ethiopia [20,31]. The risk of low birthweight was higher among mothers who did not take snacks during the current pregnancy, consistent with studies done in Ethiopia and Ghana [13, 21]. Mothers who were counselled about feeding practices during pregnancy were $88 \%$ less likely to give birth to LBW infants than their counterparts. There is mounting evidence from controlled trials that improving food intake during pregnancy effectively reduces the risk of giving birth to LBW babies [26, 27]. Similarly, iron and folic acid supplements during pregnancy had a significantly lowering incidence of LBW, in agreement with a study from Bangladesh [22]. This is further supported by a randomized, double-blind controlled trial comparing standard iron supplementation with multiple micronutrients during pregnancy [26]. Iron-alone supplementation could protect against low birthweight as compared to multiple micronutrients supplementation [26]. In addition, an overview of controlled trials suggested a

Table 3 Factors independently associated with LBW among newborns delivered in public health facilities of Nekemte town, West Ethiopia, 2017

\begin{tabular}{|c|c|c|c|c|}
\hline Variable & Case No (\%) & Controls No (\%) & COR $(95 \% \mathrm{Cl})$ & AOR (95\% Cl) \\
\hline \multicolumn{5}{|c|}{ Iron and foliate supplementation } \\
\hline Yes & $64(68.8)$ & $166(89.2)$ & 1 & 1 \\
\hline No & $29(31.2)$ & $20(10.8)$ & $3.76(1.99,7.12)$ & $2.84(1.15,7.03)$ \\
\hline \multicolumn{5}{|c|}{ Nutritional counseling } \\
\hline Yes & $40(43.0)$ & $153(82.3)$ & 1 & 1 \\
\hline No & $53(57.0)$ & $33(17.7)$ & $6.14(3.52,10.72)$ & $4.05(1.95,8.38)$ \\
\hline \multicolumn{5}{|c|}{ Taking snacks during pregnancy } \\
\hline Yes & $34(36.6)$ & $134(72)$ & 1 & 1 \\
\hline No & $59(63.4)$ & $52[27]$ & $4.47(2.63,7.61)$ & $3.25(1.64,6.44)$ \\
\hline \multicolumn{5}{|l|}{ Maternal MUAC } \\
\hline$<23$ & $49(52.7)$ & $25(13.4)$ & $7.17(3.99,12.88)$ & $5.62(2.64,11.97)$ \\
\hline$\geq 23$ & $44(47.3)$ & $161(86.6)$ & 1 & 1 \\
\hline \multicolumn{5}{|l|}{ Anemia } \\
\hline Yes & $30(32.3)$ & $17(9.1)$ & $4.73(2.44,9.17)$ & $3.54(1.46,8.61)$ \\
\hline No & $63(67.7)$ & $169(90.9)$ & 1 & 1 \\
\hline \multicolumn{5}{|c|}{ Minimum dietary diversity score of women } \\
\hline Inadequate & $87(93.5)$ & $117(62.9)$ & $8.55(3.55$ & $6.65(2.31,19.16)$ \\
\hline Adequate & $6(6.5)$ & 69 (37.1) & 20.61)1 & 1 \\
\hline
\end{tabular}


$41 \%$ decline in the prevalence of intrauterine growth retardation with folic acid supplementation [27].

Furthermore, our study reviled that anaemic mothers had higher odds to deliver LBW neonates, consistent with a study in Yemen [12]. Micronutrient deficiency during pregnancy has been shown to have serious implications on the developing foetus and hence, birthweight. Severe anaemia could impair oxygen delivery to the foetus and thus interfere with normal intrauterine growth.

Consequences of inadequate nutritional intake and poor nutritional status not only directly affect women's health status, but may also have a negative impact on birth- weight and early development. Our findings were consistent with a study from rural Oromia in Ethiopia, in which women in the inadequate MDD-W group had an increased risk of LBW and PTB [21]. Similarly, a study from Ghana showed that women dietary diversity scores and dietary patterns were found to be protective against low birthweight [13]. However, a recent randomized trial in India of increased consumption of dairy, fruits, and green leafy vegetables before and during pregnancy through a specially formulated snack had no effect on birthweight [32]. This discrepancy might be due to differences in study population, geographical location, and study design.

Main strength of this study was taking birthweight within 1 hour after birth. Measurement of some explanatory variables were, however, prone to recall bias. Finally, findings of this study can have a significant implication for prevention of low birthweight and emphasis should be given to nutrition education, nutrition assessment, supplementation of iron-folic acid and prevention of anaemia during pregnancy.

\section{Conclusion and recommendation}

Several factors were found to be associated with low birthweight. Lack of iron and folic acid supplementation, absence of nutritional counselling during pregnancy, not taking snacks during pregnancy, MUAC less than 23, maternal anaemia and inadequate MDD-W were identified to be significant predictors of LBW. Governmental and non-governmental organizations working on maternal and child health should focus on identified factors in order to tackle the problem of LBW.

\footnotetext{
Abbreviations

AOR: adjusted odds ratio; Cl: confidence interval; HFIAS: Household Food Insecurity Access Scale; LBW: Low Birthweight; MDD-W: Minimum dietary diversity score of women; MUAC: Mid upper arm circumference; VIF: Variable inflation factor; WHO: World health organization

\section{Acknowledgments}

The authors would like to express their gratitude to respective health facility, data collectors, supervisors and study participants for their diligence and dedication in the collecting and inputting high quality data used in the study.
}

Conflict interests

The authors declared no potential conflicts of interest with respect to the research, authorship, and/or publication of this article.

\section{Authors' contributions}

SG involved from the inception to design, acquisition of data, analysis and interpretation, drafting the manuscript, TF involved in the acquisition, analysis, interpretation and revision of the manuscript, EA involved in the acquisition, analysis, interpretation and revision of the manuscript, $\mathrm{DH}$ involved in the acquisition, analysis, interpretation and revision of the manuscript, GG involved in the acquisition, analysis, interpretation and revision of the manuscript, BG involved in the acquisition, analysis, interpretation and revision of the manuscript and ZD involved in the acquisition, analysis, interpretation and revision of the manuscript. All authors read and approved the final manuscript.

Funding

"Not applicable".

Availability of data and materials

All relevant data are within the paper and its Supporting Information.

Ethics approval and consent to participate

Ethical approval and clearance was obtained from Wollega university ethical review board. Informed written consent was obtained from mothers, each study participants was informed about the aim of the study and participant involvement was on voluntary basis. All neonates with low birthweight were linked to neonatal care centre in the hospitals.

\section{Consent for publication}

"Not applicable".

\section{Author details}

'Department of Psychiatry, Institute of Health, Jimma University, Jimma, Ethiopia. ${ }^{2}$ Department of Public Health, College of Medicine and Health Science, Arba Minch University, Arba Minch, Ethiopia. ${ }^{3}$ Department of Midwifery, Arba Minch College of Health Sciences, Arba Minch, Ethiopia. ${ }^{4}$ Department of Statistics, College of Natural Science, Arba Minch University, Arba Minch, Ethiopia.

Received: 22 March 2018 Accepted: 24 June 2019

Published online: 02 July 2019

References

1. UNICEF. WHO low birth-weight: country, regional and global estimates. New York: UNICEF and WHO; 2004.

2. Strategies to promote optimal fetal growth and minimize the prevalence of LBW in Sri Lanka: health sector response: Family Health Bureau ministry of health; 2013.

3. WHO. WHO global nutrition targets 2025: low birth-weight policy brief, 2014

4. Ethiopian central statistical agency, Ethiopian demographic and health survey (EDHS), Ethiopian central statistical agency: Addis Abeba, Ethiopia, 2012.

5. WHO guideline on optimal feeding of low birth-weight in low and middle income countries. Geneva, World health organization, 2011.

6. Goldenberg RL, Culhane JF. Low birth-weight in the United States. Am J Clin Nutr. 2007;85(2):5845-905.

7. Ramakrishnan U. Nutrition and low birth-weight: from research to practice. Am J Clin Nutr. 2004;79(1):17-21.

8. Barker DJP, Godfrey KM. Maternal nutrition, fetal programming and adult chronic disease. In: Gibney MJ, Margetts BM, Kearney JM, Arab L, editors. Public health nutrition. Oxford: Blackwell Science; 2004.

9. Torres-Arreola LP, Constantino-Casas P, Flores-Hernandez JPV-B, RendonMacias E. Socioeconomic factors and low birth-weight in Mexico. BMC Public Health. 2005:5(20):1-7.

10. Ghimire R, Phalke DB, Phalke VD, Banjade B, Singh AK. Determinants of low birth-weight: a case control study in Pravara rural hospital in western Maharashtra. India IJSR. 2014;3(7):2277-8179.

11. Khan A, Deeba F, Jaleel R. Frequency and risk factors of low birth-weight in term pregnancy. PJMS. 2016;32(1):138-42. 
12. Muftah S. Maternal under-nutrition and anaemia factors associated with low birth-weight babies in Yemen. Int J Community Med Public Health. 2016;3: 2749-56.

13. Abubakari A, Jahn A. Maternal dietary patterns and practices and birthweight in northern Ghana. journalpone PLOS ONE. 2016;11(9):e0162285.

14. Shakya $\mathrm{KL}$, et al. Key factors associated with low birth-weight at term in Nepal: a case control study. Int J Clin Biomed Res. 2015;1 (2):62-9.

15. Sharma SR, et al. Low birth-weight at term and its determinants in a tertiary hospital of Nepal: a case control study. PLoS One. 2015;10(4):e0123962.

16. Muchemi OM, Echoka E, Makokh A. Factors associated with low birthweight among neonates born at Olkalou district hospital, central region Kenya. Pan Afr Med J. 2015;20:108.

17. Sutan R, Mohtar M, Mahat AN, Tamil AM. Determinant of low birth-weight infants: a matched case control study. OJPM. 2014;4:91-9.

18. Kayode GA, et al. Contextual risk factors for low birth-weight: a multilevel analysis. PLoS One. 2014;9(10):e109333.

19. Coates J, Swindale A, Bilinsky P. Household food insecurity access scale (HFIAS) for measurement of household food access: Indicator guide (v.3). Washington D.C: Food and Nutrition Technical Assistance Project. Academy for Educational Development; 2007.

20. Megabiaw B, Zelalem M, Mohammed N. Incidence and correlates of low birth weight at a referral hospital in Northwest Ethiopia. Pan Afr Med J. 2012;12(4):1-8.

21. Tema T. Prevalence and determinants of low birth-weight in Jimma zone, south West Ethiopia. EAMJ. 2006:83:366-71.

22. Matin A et al. Maternal socioeconomic and nutritional determinants of low birth-weight, Shaheed Shohrawardy, medical college hospital, Dhaka, Bangladesh, J Dhaka Med Coll 2008; 17(2) : 83-87.

23. Zerfu TA, Umeta M, Baye K. Dietary diversity during pregnancy is associated with reduced risk of maternal anemia, preterm delivery, and low birthweight in a prospective cohort study in rural Ethiopia. Am J Clin Nutr. 2015; 103(6):1482-8.

24. Rizvi SA, Hatcher J, Jehan I, Qureshi R. Maternal risk factors associated with low birth-weight in Karachi: a case control study. East Mediterr Health J. 2007;13(6):1343-52.

25. Mitchell EA, Robinson E, Clark PM, Becroft DMO, Glavish N, Pattison NS, et al. Maternal nutritional risk factors for small for gestational age babies in a developed country. Arch Dis Child Fetal Neonatal Ed. 2004;89(5):F431-5.

26. Ramakrishnan U, González T, Lynnette M, Rivera J, Martorell R. Multiple micronutrient supplementation during pregnancy does not lead to greater infant birth size than does iron-only supplementation: a randomized controlled trial in a semirural community in Mexico. Am J Clin Nutr. 2003; 77(3):720-5.

27. Christian P, Keith P, Subarna K, Steven C, Elizabeth K. Joanne K et.al. Effects of maternal micronutrient supplementation on fetal loss and infant mortality: a cluster-randomized trial in Nepal. Am J Clin Nutr. 2003;78(6): 1194-202.

28. Dubey K, Nath C. An epidemiological model investigating the association between mothers nutritional status and low birth-weight in India. Health. 2016;8:251-61

29. Muthayya S. Maternal nutrition \& low birth-weight - what is really important? Indian J Med Res. 2009;130(5):600-8.

30. Kim D, Saad A. The social determinants of infant mortality and birth outcomes in western developed nations: across country systematic review. Int J Environ Res Public Health. 2013;10(6):2296-335.

31. Potdar D, Sahariah A, Gandhi M, Kehoe H, Brown N, Sane H, et al. Improving women's diet quality preconceptionally and during gestation: effects on birth-weight and prevalence of low birth-weight-a randomized controlled efficacy trial in India (Mumbai maternal nutrition project). Am J Clin Nutr. 2014;100(5):1257-68.

32. Ahmed $\mathrm{S}$, Hassen $\mathrm{K}$, Wakayo $\mathrm{T}$. A health facility based case-control study on determinants of low birth weight in Dassie town, Northeast Ethiopia: the role of nutritional factors. BMC Nutrition Journal. 2018:17:103.

\section{Publisher's Note}

Springer Nature remains neutral with regard to jurisdictional claims in published maps and institutional affiliations.

Ready to submit your research? Choose BMC and benefit from:

- fast, convenient online submission

- thorough peer review by experienced researchers in your field

- rapid publication on acceptance

- support for research data, including large and complex data types

- gold Open Access which fosters wider collaboration and increased citations

- maximum visibility for your research: over $100 \mathrm{M}$ website views per year

At BMC, research is always in progress.

Learn more biomedcentral.com/submissions 